\title{
Hvordan skrive en \\ systematisk oversikt?
}

Målgruppen for denne artikkelen er sykepleiere som $\emptyset$ nsker å lage en oversiktsartikkel over et klinisk spørsmål.

\section{Liv Merete Reinar}

Seniorrådgiver

Folkehelseinstituttet

\section{Gro Jamtvedt}

Fysioterapeut og dekan

Fakultet for helsefag, Oslomet - storbyuniversitetet

Sykepleien Forskning 20105 (3) (238-246)

DOI: 10.4220/sykepleienf.2010.0121

\section{Fakta}

En oversiktsartikkel er en artikkel som gir en oversikt over eller sammenfatning av forskningslitteratur over et definert spørsmål.

En systematisk oversikt er en oversikt som bruker systematiske og eksplisitte metoder for å identifisere, velge ut og kritisk vurdere relevant forskning samt for å samle inn, sammenstille, analysere og gradere data fra studiene som er inkludert i oversikten.

Metaanalyse er statistiske teknikker i en systematisk oversikt for å slå sammen resultatene av inkluderte studier numerisk. Brukes gjerne for å oppsummere effektmål av studier innenfor et begrenset område.

Metasyntese er en metode for å sammenstille kvalitativ forskning på et bestemt emne hvor forskerne sammenlikner og analyserer tekstene fra individuelle studier og utvikler nye tolkninger. 
Det hender sikkert at det på jobben eller under utdanning dukker opp faglige spørsmål du trenger svar på. Eksempler på slike spørsmål kan være: Hvordan kan vi på sykehjemmet best forebygge eller behandle trykksår? Trenger kvinner som nettopp har født, hjemmebes $\varnothing$ ? Hvordan kan kommunehelsetjenesten best støtte personer med demens (og deres nærmeste pårørende)?

Du $\varnothing$ nsker det beste tilgjengelige forskningsbaserte svaret. I tidsskrifter og bøker finnes det artikler om disse emnene, men unders $\varnothing$ kelsene kan være utf $\varnothing$ rt på forskjellige måter. Det er for eksempel kasuistikker, enkelterfaringer, spørreunders $\varnothing$ kelser, kvalitativt beskrivende eller utforskende studier, randomiserte studier, kvasirandomiserte studier og studier med kvalitative metoder, som fenomenologiske studier.

Og det finnes mange typer oversiktsartikler. Mange oversiktsartikler er godt skrevet og har troverdig innhold; de er skrevet av personer med innsikt i og engasjement for emnet.

Men ofte mangler oversiktsartiklene en tydelig metodebeskrivelse. Det kan for eksempel være usikkert hvordan forfatterne har lett etter forskning, og om forfatterne gjennom ikke-systematisk utvelging kun har valgt forskningsstudier som st $\varnothing t t e r$ ett gitt syn eller én bestemt type behandling.

Dette kan gi et ubalansert og skjevt bilde av tilgjengelig forskning. Som sykepleier er du derfor ikke trygg på om resultatene eller rådene som gis, er til å stole på.

Å basere praksis på én enkelt studie kan også bære galt av sted (1). Én enkelt studie kan ha fă deltakere, og funnene kan være basert på tilfeldigheter, skjevheter i utvalget og mange andre forhold. Dette fører til at studier om samme emne kan ha ulike konklusjoner. 
Sykepleiere bør derfor i størst mulig grad basere sin praksis på funn fra systematiske oversikter. En systematisk oversikt er en oversiktsartikkel der forfatterne har brukt en systematisk og åpen fremgangsmåte for å finne, vurdere og oppsummere flere primærstudier om samme problemstilling $(2,3)$.

Systematiske oversikter kjennetegnes ved at de har

- en klar tittel og et klart formål

- en omfattende, eksplisitt beskrevet søkestrategi

- klare kriterier for inklusjon og eksklusjon av primærstudier

- vurdering av validitet, kvalitet eller risiko for systematiske skjevheter på inkluderte studier

- protokollføring av karakteristiske trekk for alle inkluderte studier

- sammenstilling av resultatene fra inkluderte studier (4)

Det er viktig at leseren i størst mulig grad kan stole på resultatene som fremkommer av oversikten. Dette fordrer en tydelig og eksplisitt metodebeskrivelse. Leserne skal ha mulighet til å etterprøve og vurdere det som er gjort, med et kritisk blikk. Les gjerne mer i metodeb $\varnothing$ ker (2-7).

En systematisk oversikt bør også følge IMRADstrukturen: introduksjon, metode, resultater, diskusjon og konklusjon $(8,9)$. I innledningen skal det tydeliggiøres hvorfor spørsmålet som stilles, er viktig, og rasjonalet for spørsmålet i lys av det som allerede er kjent om emnet i forskningslitteraturen.

I metodedelen skal du beskrive fremgangsmåten så eksplisitt og tydelig som mulig, og i resultatdelen skal du skrive hva du fant, og hva det totale bildet sier. I diskusjonsdelen skal funnene diskuteres opp mot annen relevant kunnskap. Uansett, det hele starter med en plan, disposisjon eller protokoll. 


\section{Fakta}

\section{Formulere spørsmål}

- spesifisere: populasjon (hvem), tiltak, eksposisjon eller fenomen (hva), utfallsmål, endepunkter, metodologi/studiedesign (hvordan)

- spesifisere inklusjons- og eksklusjonskriterier

- bestemme eventuelle restriksjoner som tidsramme (publikasjonsår), upubliserte data og språk

\section{Gjøre litteratursøk}

- bestemme informasjonskilder: bibliografiske databaser, hånds $\varnothing \mathrm{k}$ av tidsskrifter, gjennomgå referanselister, kontakte eksperter, kontakt med industrien, egne arkiver, institusjonen som eventuelt finansierer arbeidet, registre

- identifisere titler og sammendrag

\section{Anvende inklusjons- og eksklusjonskriterier}

- bruke inklusjons- og eksklusjonskriteriene på titler og sammendrag (gjøres av én person eller flere uavhengig av hverandre?)

- innhente artikler i fulltekst basert på titler og sammendrag

- bruke inklusjons- og eksklusjonskriterier på fulltekstartikler (gjøres av én eller flere personer?)

- velge ut studier som oppfyller inklusjonskriteriene

\section{Hente ut data}

- vurdere metodisk kvalitet på studiene (vurdering av validitet og reliabilitet). Hvilke kriterier skal brukes? Gjøres det av flere personer uavhengig av hverandre?

- sammenfatte data fra hver inkludert studie om deltakere, tiltak/eksposisjon/fenomen, studiedesign, dataekstraksjonsskjema

- sammenfatte resultater

\section{Analysere data}

- vurdere heterogenitet

- bestemme hvilken metode som skal brukes for å oppsummere resultatene

- slå sammen resultatene i metaanalyser (hvis hensiktsmessig). Metasynteser av kvalitative studier. Eventuell beskrivende narrativ / kvalitativ oppsummering 


\section{Protokoll}

Protokollen er en plan for hvordan du skal gå frem for å finne, vurdere og sammenfatte forskning om et emne (1). Her følger en huskeliste som kan brukes når du skriver disposisjon og planlegger et slikt arbeid. Denne huskelisten for protokoll er hentet og tilpasset fra DiCenso og Guyatt (1). For å lære mer om spørsmålsformulering ved hjelp av PICO (populasjon, intervensjon, kontroll og utfall) og om kjernespørsmål $i$ helsetjenesten, se annen litteratur $(10,11)$.

I prinsippet kan du skrive en systematisk oversikt over alle typer spørsmål. Du kan også lese mer om hvilke studiedesign som er best egnet til å besvare ulike typer spørsmål (4, 11). Dette er kunnskap som er grunnleggende og viktig å ha $\mathrm{i}$ «bunn» før du går i gang med en systematisk oversikt.

I Cochrane Library (12) finner du mange publiserte protokoller. Det kan være nyttig å kikke på disse av minst to grunner: Du kan finne ut hvordan en god protokoll ser ut, og du kan finne ut hvilke systematiske oversikter som er på gang (og eventuelt unngå dobbeltarbeid).

\section{Rapportering}

Stadig flere tidsskrifter setter krav til hva slags oversiktsartikler de publiserer, og stiller også klare metodiske krav til artiklene. Likevel er det ulike krav til systematikk i de forskjellige tidsskriftene. Se for eksempel Journal of Advanced Nursing (13) og Tidsskrift for Den norske legeforening (14). Se også Joanna Briggs Library (15).

Som i alle vitenskapelige disipliner er metoder for systematiske oversikter også gjenstand for revisjon og nytenkning. I 2009 kom en artikkel med forfattere fra mange miljøer, «The PRISMA statement for reporting systematic reviews and meta-analyses of studies that evaluate healthcare interventions: explanation and elaboration» (16). 
Artikkelen er en 27-punkts sjekkliste for hva som hører med når en systematisk oversikt skrives, hvordan det som er gjort, bør rapporteres i en publikasjon. Det er verdt å kjenne til denne sjekklisten - selv om ikke alle krav kan oppfylles hver gang. I tillegg gir PRISMAartikkelen eksempler på hvordan figurer og tabeller kan utformes (17). I det følgende skisserer vi noen vesentlige punkter og kommer med eksempler på hvordan man kan formulere seg i en systematisk oversikt.

\section{Tittel}

Skriv i tittelen at det er en systematisk oversikt, og legg eventuelt til hva slags type studier som er med i oversikten. For eksempel: «Tiltak for å forebygge fall hos eldre i sykehjem - en systematisk oversikt over kontrollerte studier».

Ideelt sett bør også PICO-en være tydelig i tittelen det bør altså komme frem hvilken pasientgruppe, hvilken behandling eller hvilket fenomen som er i fokus, og hvilke utfall som rapporteres, for eksempel slik: «Effekten på atferd av musikkterapi til personer med demens - en systematisk oversikt over randomiserte kontrollerte studier».

\section{Inklusjonskriterier}

Spesifiser studiekarakteristika for de forskningsartiklene du lette etter og inkluderte. Det skal rapporteres hvilken populasjon, hvilket tiltak eller fenomen eller eksposisjon som ble studert, om det var noen kontrolltiltak, og hvilke utfall som skulle måles (dersom du skriver en oversikt om effekt av tiltak).

Inklusjonskriterier omfatter også å rapportere om studier skulle være publisert innen visse tidsrom, være publisert på enkelte språk, være publisert i spesielle tidsskrifter eller ha en spesiell publikasjonsstatus (for eksempel vitenskapelige tidsskrifter eller doktoravhandlinger). Det må også tydeliggjøres hvilke studiedesign som skulle tas med. Det bør også synliggjøres hvilke eksklusjonskriterier som ble brukt. 


\section{Søkestrategi}

Det må komme tydelig frem hvor du har lett etter forskningsartikler. List opp hvilke databaser som det er søkt i (for eksempel Medline, Embase, Cochrane Central, Cinahl, PsycLIT eller Pedro). Nevn også om du har kontaktet eksperter, eller har gjennoms $\varnothing \mathrm{kt}$ bestemte tidsskrifter (håndsøk) eller har gått gjennom referanselister på artikler som er identifisert.

En systematisk oversikt skal også ha en eksplisitt, tydelig og referert s $\varnothing$ kestrategi. Det skal rapporteres hvilke søketermer som ble brukt, og hvordan disse ble kombinert. Se metodebeskrivelsene i for eksempel artiklene til Hjälmhult eller Bragstad og Kirkevold i Sykepleien Forskning eller PRISMA-artikkelen (16, 18, 19).

Etter at søket etter litteratur er gjennomført, skal det foretas en studieseleksjon, det vil si å bestemme hvilke studier som skal med i oversikten, og hvilke som ikke skal med (ekskluderes). Beskriv hvordan dette ble gjort. Ble det gjort av én person eller av flere uavhengig av hverandre? Ble første seleksjon gjort basert på titler og sammendrag?

\section{Kvalitetsvurdering}

Et svært viktig trinn $i$ arbeidet med en systematisk oversikt er vurdering av risiko for systematiske skjevheter (bias) i hver studie. Studiene må vurderes med tanke på metodisk kvalitet. Hvordan er studien utført, og hvilke kriterier ble brukt? Ulike studiedesign bør vurderes ut fra egne, på forhånd gitte kriterier. Du må vurdere og bestemme hvilke kriterier som er viktigst ut fra hvilket spørsmål oversikten $\varnothing$ nsker å besvare. 
Det finnes mange publiserte sjekklister og verktøy som kan brukes i denne kvalitetsvurderingen. Norske sjekklister finnes på helsebiblioteket.no/kunnskapsbasert-praksis. For å redusere faren for subjektive vurderinger bør en slik kvalitetsvurdering gjøres av minst to personer uavhengig av hverandre. Eksempler på viktige vurderinger for ulike spørsmål/ design (1):

Effekt: Reduserer musikkterapi utagerende atferd hos personer med demens?

- Ble pasientene randomisert?

- Var gruppene like med hensyn til alle kjente bakgrunnsfaktorer for utfallet, eller ble det justert for forskjeller?

- Var oppfølgingen komplett nok (akseptabel)?

Diagnose: Er øretermometer like pålitelig som rektaltermometer for å diagnostisere feber hos barn?

- Var den diagnostiske testen brukt på pasienter som kunne ha fra lav til høy sannsynlighet for å ha den aktuelle tilstanden?

- Var det en blindet sammenlikning med en referansetest (gullstandard) som ble brukt likt for alle pasienter?

Prognose: Hvordan er skoleprestasjonene til barn som er født i 26. svangerskapsuke?

- Var utvalget av deltakere representativt?

- Var deltakerne like nok (homogene) når det gjaldt prognoserisiko?

- Var oppfølgingen komplett nok (akseptabel)?

Kvalitativ: Hva opplever intensivsykepleiere som utfordrende ved avsluttende behandling $\mathrm{i}$ intensivavdelingen?

- Er det tilfredsstillende beskrevet hvordan og hvorfor utvalget ble valgt? 
- Var datainnsamlingen tilstrekkelig for å gi et helhetlig bilde av fenomenet?

- Ble det redegjort for bakgrunnsforhold hos forskeren som kan ha påvirket fortolkningen av dataene?

- Går det klart frem hvordan analysen ble gjennomført?

Kartlegging: Hvor mange fall blant eldre fører til alvorlige skader?

- Ble utvalget inkludert i studien på en tilfredsstillende måte?

- Er svarprosenten høy nok?

- Bruker studien målemetoder som er pålitelige (valide) for det man ønsker å måle?

\section{Dataekstraksjon}

Gjør rede for metoden som ble brukt da data ble hentet ut fra inkluderte studier. Ble det laget et dataekstraksjonsskjema? Ble dataekstraksjonen gjort av én eller flere personer? Det bør komme frem hvilke data som ble hentet ut fra hver artikkel, for eksempel studiedesign, pasientgruppe, tiltak, kontrollgruppe, antall deltakere, setting, dosering, oppfølgingstid, utfallsmål og opplysninger om hvordan utfall ble målt.

\section{Resultatrapportering}

Etter at metoden er beskrevet i metodeavsnittet, skal funnene eller resultatene rapporteres under resultater. Det må komme frem hvor mange treff det var etter $s ø k$ i alle kilder, og hvor mange artikler som ble innhentet og vurdert basert på tittel og sammendrag. Til slutt må det være en setning som sier hvor mange artikler som ble inkludert.

En figur med artikkelflyt kan gi en god oversikt over denne prosessen. Se eksempel i figur 1. Se også artikkelen til Hjälmhult eller Bragstad og Kirkevold $(18,19)$. 


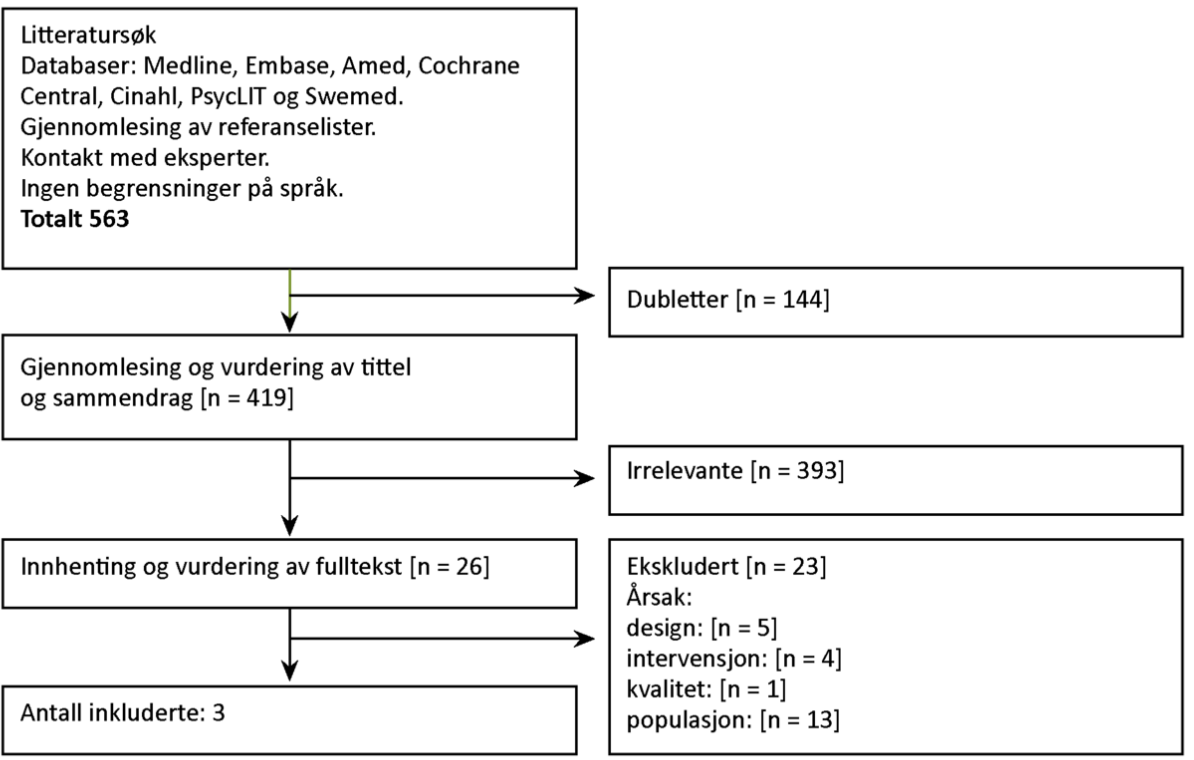

Det hører også med å angi karakteristika for alle inkluderte studier. Beskriv metode og design, deltakere, tiltak og utfall, gjerne med henvisning til en tabell med karakteristika over inkluderte studier. Se eksempel i tabell 1.

\begin{tabular}{|c|c|c|c|c|c|c|c|}
\hline Studie & Design & Setting & Deltakere & Tiltak & Kontroll & Utfallsmål & Resultat \\
\hline Clark 1998 & Crossover & $\begin{array}{l}\text { Sykehjem } \\
\text { USA }\end{array}$ & 18, demente & $\begin{array}{l}\text { Individuali- } \\
\text { sert musikk- } \\
\text { terapi }\end{array}$ & $\begin{array}{l}\text { Standard } \\
\text { behandling }\end{array}$ & $\begin{array}{l}\text { Agressiv } \\
\text { atferd }\end{array}$ & $\begin{array}{l}\text { Færre til- } \\
\text { feller agres- } \\
\text { sivatferd } \\
\text { i tiltaks- } \\
\text { gruppen }\end{array}$ \\
\hline Cohen 1997 & Crossover & $\begin{array}{l}\text { Sykehjem } \\
\text { USA }\end{array}$ & $\begin{array}{l}\text { 37, demente } \\
\text { (?) }\end{array}$ & $\begin{array}{l}\text { Idividualisert } \\
\text { musikk- } \\
\text { terapi, sosial } \\
\text { interaksjon } \\
\text { med familie- } \\
\text { medlemmer }\end{array}$ & $\begin{array}{l}\text { Standard } \\
\text { behandling }\end{array}$ & $\begin{array}{l}\text { Verbal } \\
\text { forstyrrende } \\
\text { atferd }\end{array}$ & $\begin{array}{l}\text { Signifikant } \\
\text { mindre } \\
\text { agressiv } \\
\text { atferd i } \\
\text { tiltaks- } \\
\text { gruppen }\end{array}$ \\
\hline Garlan 2007 & Crossover & $\begin{array}{l}\text { Sykehjem } \\
\text { Australia }\end{array}$ & 30, demente & $\begin{array}{l}\text { Indivi- } \\
\text { dualisert } \\
\text { psykososial } \\
\text { intervensjon }\end{array}$ & $\begin{array}{l}\text { Annen indi- } \\
\text { vidualisert } \\
\text { psykososial } \\
\text { intervensjon }\end{array}$ & $\begin{array}{l}\text { Fysisk } \\
\text { og verbal } \\
\text { agitert atferd }\end{array}$ & $\begin{array}{l}\text { Ingen klar } \\
\text { forskjell } \\
\text { mellom } \\
\text { gruppene }\end{array}$ \\
\hline
\end{tabular}

\section{Kvalitetsvurdering av inkluderte studier}

Du må redegjøre for den metodiske kvaliteten på studier som ble inkludert. Dette bør gjøres så eksplisitt som mulig. Det bør komme frem hvilke inkluderte studier som hadde metodiske svakheter og begrensninger, og hvorfor. For å være helt tydelig på hvilke kriterier artiklene er vurdert etter, kan det beskrives i en tabell. Se eksempel i tabell 2. 


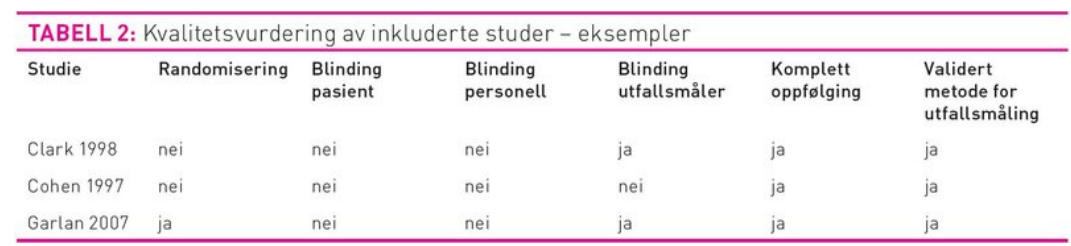

\section{Metaanalyser}

Når resultatene i en systematisk oversikt skal sammenstilles, er det noen ganger hensiktsmessig å lage en metaanalyse. Da slår man sammen effektestimater fra flere studier til ett felles effektestimat.

Det er mange forutsetninger som bør være oppfylt før dette er riktig og forsvarlig. En slik kvantitativ syntese forutsetter at primærstudiene er like nok, for eksempel at forskerne har unders $\varnothing \mathrm{kt}$ samme spørsmål på et likt nok utvalg, og at man har målt utfall på samme måte. Dersom du gjør en metaanalyse, er det god veiledning i Cochrane Handbook (4). Samtidig kan det være nyttig å ha en statistiker med på laget!

\section{Metasynteser}

Å lage systematiske oversikter basert på kvalitative studier (metasynteser) er en forholdsvis ny metode. Det foregår gode diskusjoner i fagmiljøer om og hvordan dette gjøres mest hensiktsmessig. Foreløpig foreligger det ikke full enighet $\mathrm{i}$ fagmiljøene, og metasynteser er kontroversielle.

Men et miljø som har drevet fagutvikling på området, er Joanna Briggs Institute i Australia (6). De fremhever at mange forskere setter spørsmål ved metoden blant annet på grunn av den kvalitative forskningens subjektive natur. Mange forskere med erfaring fra kvalitativ forskning er også kritiske på grunn av de ideologiske, filosofiske og metodiske særegenhetene som karakteriserer den kvalitative forskertradisjonen. Noen mener at en syntese av kvalitative studier er umulig og meningsløs. Andre mener at slike synteser kan gi nyttig kunnskap til helsefagene. 
Joanna Briggs manual beskriver et par ulike tilnærminger for eventuelle metasynteser (15), Qualitative Assessment and Review Instrument (QARI) og såkalt meta-etnografi. Med QARI bruker man tre steg: 1) identifisere funn, 2) gruppere funn $i$ kategorier og 3) gruppere kategorier til synteser av funn.

Det er nylig kommet en ny norsk bok som handler om kvalitativ metasyntese (20). Forfatteren beskriver hvordan du kan få oversikt over eksisterende kvalitativ forskning og bygge på denne i en analyse og sammenstilling (syntese).

\section{Oppsummering}

I denne artikkelen har vi kort gått gjennom de ulike trinnene som hører med når man lager en systematisk oversikt. Artikkelen gir ikke utdypende informasjon om dette. Referansene gitt i artikkelen kan være til god hjelp dersom du ønsker å fordype deg mer.

\section{Referanser}

1. Ciliska D, DiCenso A, Guaytt G. Summarizing the evidence through systematic reviews. I: DiCenso A, Guyatt G, Ciliska D, red. Evidencebased nursing: a guide to clinical practice. St. Louis: Elsevier Mosby; 2005. s. 137-53.

2. Folkehelseinstituttet. Slik oppsummerer vi forskning [internett]. Oslo: Nasjonalt kunnskapssenter for helsetjenesten; 04.10.2014 [sitert 23.05.2018]. Tilgjengelig fra:

https://www.fhi.no/kk/oppsummert-forskning-forhelsetjenesten/slik-oppsummerer-vi-forskning/.

3. Greenhalgh T. How to read a paper - the basics of evidence-based medicine. 4. utg. Oxford: Wiley \& Blackwell Publishing, BMJ-books; 2010. 
4. Higgins JPT, Green S, red. Cochrane handbook for systematic reviews of interventions. Versjon 5.1.0 [oppdatert mars 2011]. The Cochrane Collaboration; 2011. Tilgjengelig fra: http://handbook.cochrane.org (nedlastet 08.06.2018).

5. Egger M, Smith G, Altman D. Systematic reviews in health care - meta-analysis in context. 2. utg. London: BMJ Publishing Group; 2001.

6. Aromataris E, Munn Z, red. Joanna Briggs Institute reviewer's manual. The Adelaide: Joanna Briggs Institute; 2017. Tilgjengelig fra: https://reviewersmanual.joannabriggs.org/ (nedlastet 07.08 2019).

7. DiCenso A, Guaytt G, Ciliska D. Evidencebased nursing: a guide to clinical practice. St. Louis: Elsevier Mosby; 2005.

8. Nylenna M. IMRAD - et hjelpemiddel i vitenskapelig publisering. Sykepleien Forskning. 2009;4(3):172-3.

9. Reinar LM, Korn $\varnothing \mathbf{r}$ H. Skriv en artikkel. Sykepleien Forskning. 2007;2(1):62-3.

10. Kunnskapsbasertpraksis.no. [internett]. Oslo: Folkehelseinstituttet; [sitert 23.05.2018]. Tilgjengelig fra: http://www.helsebiblioteket.no/kunnskapsbasertpraksis.

11. Nortvedt MW, Jamtvedt G, Graverholt B, Nordheim LV, Reinar LM. Jobb kunnskapsbasert! En arbeidsbok. 2. utg. Oslo: Akribe; 2012.

12. Cochrane Library. Tilgjengelig fra: http://www.helsebiblioteket.no/oppsummertforskning og https://www.cochranelibrary.com/ (nedlastet 23.05.2018). 
13. Journal of Advanced Nursing. Systematic

review or other type of review paper [internett].

Wiley Online Library; juni 2018 [sitert 23.05.2018].

Tilgjengelig fra:

https://onlinelibrary.wiley.com/page/journal/136526

48/homepage/systematic_review_or_other_type_of

_review_paper.htm.

14. Tidsskrift for Den norske legeforening.

Oversiktsartikkel [internett]. Oslo: Tidsskrift for

Den norske legeforening; [sitert 23.05.2018].

Tilgjengelig fra:

https://tidsskriftet.no/annet/oversiktsartikkel.

15. The University of Adelaide, Joanna Briggs

Institute. Joanna Briggs' Library. Adelaide; 2019.

Tilgjengelig fra: https://joannabriggs.org/ (nedlastet

18.11.2019).

16. Liberati A, Altman D, Tetzlaff J, Mulrow C,

Gøtzsche P, Ioannidis J, et al. The PRISMA

statement for reporting systematic reviews and meta-analyses of studies that evaluate healthcare interventions: explanation and elaboration. PLoS Medicine. 2009;6(7).

17. PRISMA. Transparent reporting of systematic reviews and meta-analyses [internett]. PRISMA; [sitert 23.05.2018]. Tilgjengelig fra:

http://www.prisma-statement.org/.

18. Hjälmhult E. Skal helses $ø$ ster tilby hjemmebes $\varnothing \mathrm{k}$ til alle foreldre med nyfødt barn? Sykepleien Forskning. 2009;4(1):18-26.

19. Bragstad L, Kirkevold M. Individualisert musikk for personer med demens. Sykepleien Forskning. 2010;5(2):110-8.

20. Malterud K. Kvalitativ metasyntese som forskningsmetode i medisin og helsefag. Oslo: Universitetsforlaget; 2017. 
